\title{
Result Analysis of the Local FCE Examination Sessions (2013-2014) at Tomsk Polytechnic University
}

\author{
Oksana P. Kabrysheva
}

National Research Tomsk Polytechnic University, Email: okskabr@tpu.ru

Uliana A. Smirnova

National Research Tomsk Polytechnic University, Email: ulsmirnova@yandex.ru

Angelina V.Vasileva

National Research Tomsk Polytechnic University, Email: gelya_vasileva@mail.ru

Doi:10.5901/mjss.2015.v6n3s1p239

\begin{abstract}
In this article the authors cover main international English Language Examinations, their role in defining language proficiency and interpreting language qualifications and review the structure of English as a foreign language examination FCE (First Certificate in English). The applied part of the paper contains the result analysis of this examination at Tomsk Polytechnic University (local sessions 2013 and 2014) and is aimed at identifying the most complicated papers of the exam and the relationship between English proficiency and the difficulties detected (based on certificate grades). Theoretical analysis of methodological literature, mathematical research methods for data and results processing, as well as authors' personal experience of administering local EFL examination sessions were used. The obtained results allow us to conclude that in productive skills there is no relationship between certificate grade and difficulty in Writing and Speaking papers of the test. The Listening paper was considered to be the most difficult. The following relationship is revealed: the lower English proficiency a candidate has, the more interference of the gaps in the student's knowledge in different examination papers is observed, therefore, the greater difficulty he/she encounters when completing examination questions. This work will be useful for language teachers, graduate students, students of English who are preparing for the FCE exam.
\end{abstract}

Keywords: international examination, examination paper, result analysis, difficulty.

\section{International English Language Examinations in Defining Language Proficiency and Interpreting Language Qualifications}

Nowadays many learners have been studying English but do not know what language proficiency level they have. It might mean English fluency or reading English books or a high score in English. However, reading English books, language fluency and high scores in English cannot be used as a tool of measurement. Thus, the understanding of language proficiency is vague. International certification examinations can structure the knowledge to determine the level of English proficiency, and quite clearly, in accordance with international standards, reflect how well learners know it and what purposes learners can use this knowledge for.

The processes of globalization that have occurred in recent decades in Europe led to the fact that many language testing organizations in Europe have been united in an association - ALTE (the Association of Language Testers in Europe) members of which exist in 28 countries. The Examination Board of the University of Cambridge - Cambridge English Language Assessment became one of the founders of the Association. Working together they designed the scale of the Council of Europe published under the title "Common European Framework of Reference for Languages" which serves not only as a single measurement scale but also a necessary basis for curriculum development, multi-level educational facilities and examination papers for European countries (Common European Framework of Reference for Languages: Learning, teaching, assessment, 2001). In Europe international exams such as Cambridge English Language Assessment exams are used in the state secondary and higher education and are the basis for the development of national qualification exams.

The main reason for the growing number of candidates who take English exams and get an international certificate 
in Russia is increasing labor and academic mobility. The certificate confirming a certain level of English proficiency is the main condition for admission to overseas educational institutions and international employment.

Such certificate is also necessary for employees aimed at promotion in Russia. The best way to prove English proficiency is to get an international certificate, which will mean only one thing in any country in the world - English can be used effectively for work or study.

\section{International English Language Examinations Overview}

\subsection{Test of English as a Foreign Language}

TOEFL (Test of English as a Foreign Language) which became the very first international test of English as a foreign language that appeared in Russia evaluates basic English language skills. TOEFL is one of the most well-known standardized tests developed by American testing service ETS (Educational Testing Service) at Princeton University in the USA in 1960s.

TOEFL certificate is a prerequisite for admission to more than 2400 colleges and universities in the USA, Canada and other countries. TOEFL is used to evaluate English proficiency by government agencies, international organizations that provide educational grants, as well as a variety of licensing and certification organizations around the world. It is also recognized in the UK, and in this country there are several exam centres.

TOEFL is a specific exam. First, this is a test of American English with all its lexical and grammatical peculiarities. Second, TOEFL scores are valid for two years. In 1998 in most countries, paper-based TOEFL was replaced by computer option: "computer- based" TOEFL containing fewer questions with maximum score equal to 120 . The test consists of reading, listening, writing and speaking implied to be completed in 4,5 hours.

\subsection{International English Language Testing System}

International English Language Testing System (IELTS) is equally popular worldwide. The test is designed and ideal for assessing language skills of candidates who are going to live, study or work abroad, particularly in Australia, Canada and New Zealand.

Introduced in 1990, IELTS has become one of the first integrated testing systems of all four language skills in English. And nowadays IELTS sets the standards for English testing. Nearly 5,000 organizations and over 1700000 people who pass the test all over the world annually trust and recognize IELTS as a reliable indicator of basic communication skills necessary for education, immigration and professional accreditation in an English-speaking environment.

International IELTS exam is administered by the British Council, IDP: IELTS Australia and Cambridge English Language Assessment through more than 350 offices in 120 countries. The format of IELTS is designed to assess all language skills. The structure of the exam which lasts 2 hours and 45 minutes includes four sections, each of which assesses 4 main language skills of the candidate: listening, reading, writing, speaking. "Reading" and "Writing" are presented by two versions: the Academic Module and the General Training Module. IELTS scores are valid for two years.

\subsection{Cambridge English Language Assessment Examinations}

Cambridge English Language Assessment examinations are considered to be the most popular international English language exams in the world at the moment. Cambridge English Language Assessment is one of the branches of the world famous Cambridge University and its certificates are recognized by universities and employers of 80 countries as a proof of English proficiency. Examples of educational institutions and governments that recognize Cambridge English Language Assessment certificates for immigration, employment of personnel in government agencies and training of teachers for state educational institutions are Harvard University (Harvard Business School), The Sorbonne, University of Cambridge, Governments of Australia, Canada, China, the Netherlands, Switzerland, the UK, the USA. Each Cambridge certificate is an achievement which indicates something distinctive about its owner and his skills (http://www. cambridgeenglish.org/why-cambridge-english/global-recognition/index.aspx?s=1).

Cambridge English Language Assessment is a founder member of the Association of Language Testers in Europe (ALTE), and Cambridge exams are based on the principles and approaches of the Common European Framework of Reference for Languages (CEFR) - the standard benchmark used internationally to describe language ability. This means that instead of a simple test to check what students have learned, students are given a test to identify what 
language users can typically do at different levels and in different contexts (general, social and travel, work or study).

Cambridge exams are an independent system of assessment of the English language proficiency and skills which has been developed and perfected in the UK for nearly one hundred years. The first test of English as a foreign language was introduced in Cambridge in 1913. It was based on long experience in developing and conducting tests on a wide range of scientific disciplines for the purpose of which the University of Cambridge Local Examinations Syndicate (UCLES) was created in 1858.

Cambridge English Language Assessment has the largest in the UK team of professionals specializing in language assessment. This team has been researching all aspects of Cambridge English Language Assessment to ensure the reliability, objectivity and quality control of the examinations.

Every year 1.5 million people in the world take different Cambridge English examinations (http://www.cambridge english.org/2. In case they pass an examination, they receive a certificate which is life-long valid as a university diploma. It is also important that Cambridge exams are being constantly revised and improved on the basis of research in the fields of psychometrics and language testing. The results of these studies are regularly published and used by specialists from other countries to create better measuring tools within national education systems (Portuguese schools to use Cambridge English as part of national scheme, 2014). Russia also resorts to the same description of the competencies in the development of the Unified State Exam in foreign languages. The levels at the junction of which the State Exam is located, are defined as B1 and B2 which corresponds to the PET and FCE examinations. In addition, many Russian universities, especially linguistic ones, take the same CEFR levels as the basis for curriculum design.

Cambridge Syndicate performs a detailed study and analysis of students' works to ensure the reliability of examinations in respect to all candidates regardless of their nationality, mother tongue or gender. All the examination questions and assignments are designed to assess real abilities of the examinee. An important element of the Cambridge examination system is a computer database of all the exams where the results for all the examinations passed are recorded and processed. This database - Cambridge Learner Corpus, jointly developed by Cambridge English Language Assessment and Cambridge University Press, includes more than 60000 real exam works performed throughout the world. Errors in exam papers are marked in a special way in accordance with a special system of error coding through which you can see what words and grammatical forms and types of tasks cause most mistakes at a particular examination level. This information is used in the development of textbooks and dictionaries.

Alongside with general English qualifications, Cambridge English Language Assessment provides examinations in business English - Business English Certificates (BEC) designed for candidates with different levels of language proficiency - from Intermediate to Advanced. They determine the level of business English proficiency and are required in the field of international business.

In addition to examinations in English as a foreign language Cambridge English Language Assessment has developed a series of teaching qualifications. One of these examinations is Teaching Knowledge Test (TKT) which focuses on teaching knowledge. There are 4 core modules:

Module 1 - Background to language teaching

Module 2 - Planning for language teaching

Module 3 - Classroom management

TKT Practical - Assessment of teaching competence

Specialist modules:

- TKT: Content and Language Integrated Learning - A test of the understanding of existing approaches to teaching curriculum subjects through the medium of a second or third language.

- TKT: Knowledge About Language - A test of knowledge and understanding of the systems of language from a teaching perspective.

- TKT: Young Learners - A test of the background knowledge related to teaching young learners in the 6-12 age range.

The results are reported in 4 bands:

1 - restricted knowledge of areas on the TKT Module

2 - basic knowledge of areas on the TKT Module

3 - generally comprehensive and accurate knowledge of areas on the TKT Module

4 - comprehensive and accurate knowledge of all areas on the TKT.

Candidates will receive a certificate for each module taken. The advantage of this test is that TKT modules can be taken separately. 


\section{Cambridge First Certificate in English}

At Tomsk Polytechnic University the most popular international English examinations at the moment are Cambridge English Language Assessment exams, especially FCE. Cambridge First Certificate in English (FCE) is aligned to the third stage of 5-level Cambridge English Language Assessment system and corresponds to CEFR level B2 - Independent User. It is a qualification at upper-intermediate level. Until 2014 the exam consisted of five sections: Reading, Writing, Use of English, Listening and Speaking. After the revision of the format, since January 2015 the examination comprises 4 sections (Cambridge English: First - First Certificate in English (FCE) CEFR Level B2. Handbook for Teachers, 2013 and Specifications and Sample Papers for examinations from January 2015, 2013).

\subsection{FCE Marks and results}

Results are measured as a sum of scores in five sections. Candidates may receive certificates with the following grades: A (80\% or more correct answers), B (75-79\%) and C (60-74\%). Candidates with 56-59\% of correct answers will get a B1 CEFR level certificate (NOT FCE certificate). The results for each exam paper are presented in Statement of Results with assessment profile as follows: Weak (poor performance), Borderline (satisfactory performance), Good (good performance) and Exceptional (excellent performance) (Cambridge English: First - First Certificate in English (FCE) CEFR Level B2. Handbook for Teachers, 2012).

\section{Treatment and Assessments}

The objective was to identify problem areas and determine whether there is a relationship between the candidates' results in various exam papers and certificate grades. The following research methods were used: theoretical analysis of methodological literature (Hughes A., 2000; Madsen H., 1983), mathematical research methods for data and results processing (Alderson J., 1999; Bachman L., 1997), many years' personal experience of administering local FCE examination sessions at Tomsk Polytechnic University.

The FCE Cambridge examination was administered to 45 candidates during the local sessions at Tomsk Polytechnic University in 2013-2014. The examination results are presented in Figure 1 which shows that most candidates received a certificate with grade C - $36 \%$ (16 candidates). A certificate with grade B and B1 level was received by $24 \%$ (11 candidates) and $27 \%$ (12 candidates), respectively.

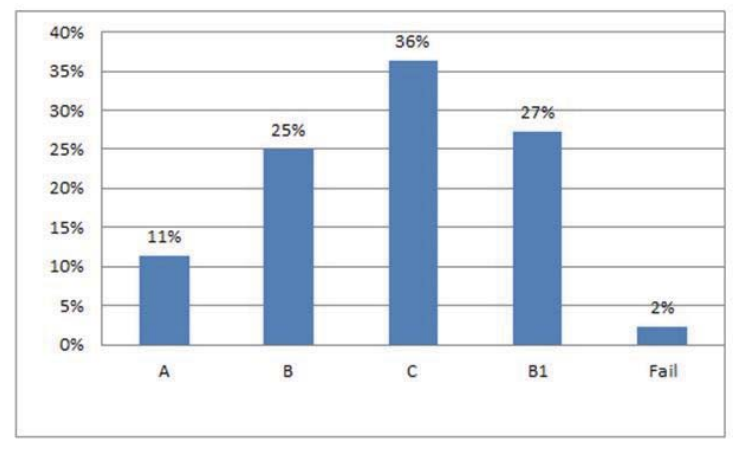

Figure 1. FCE results in 2013-2014

In order to identify the papers of the test, causing the greatest difficulty in the candidates, the Statements of results were analyzed. The obtained data is presented below in Tables 1, 2 and 3.

Table 1

\begin{tabular}{|c|c|c|c|c|c|c|c|}
\hline \multicolumn{4}{|c|}{ Reading } & \multicolumn{4}{c|}{ Writing } \\
\hline Weak & Boderline & Good & Exceptional & Weak & Boderline & Good & Exceptional \\
\hline $23 \%$ & $32 \%$ & $18 \%$ & $27 \%$ & $7 \%$ & $45 \%$ & $25 \%$ & $20 \%$ \\
\hline
\end{tabular}


Table 2

\begin{tabular}{|c|c|c|c|c|c|c|c|}
\hline \multicolumn{4}{|c|}{ Use of English } & \multicolumn{4}{c|}{ Listening } \\
\hline Weak & Boderline & Good & Exceptional & Weak & Boderline & Good & Exceptional \\
\hline $23 \%$ & $34 \%$ & $23 \%$ & $20 \%$ & $36 \%$ & $27 \%$ & $16 \%$ & $18 \%$ \\
\hline
\end{tabular}

Table 3

\begin{tabular}{|c|c|c|c|}
\hline \multicolumn{4}{|c|}{ Speaking } \\
\hline Weak & Boderline & Good & Exceptional \\
\hline $2 \%$ & $34 \%$ & $50 \%$ & $14 \%$ \\
\hline
\end{tabular}

From the above tables 1, 2, 3 it is seen that Listening paper is the most difficult - $36 \%$ of the candidates failed to complete it at the required level, the task performance in this paper has been assessed as "Weak". At the same time it was found out that the least difficult papers are Writing and Speaking, as the smallest number of candidates got "Weak" $7 \%$ and $2 \%$ respectively, whereas the majority of the candidates performed at "Borderline" - $45 \%$ in the Writing Paper and $34 \%$ in the Speaking one. In comparison to that, in the Reading and Use of English papers it was observed that 32\% and $34 \%$ of the candidates performed at "Borderline". Analyzing the highest performance in each exam paper we see that $27 \%$ of the candidates demonstrated "Exceptional" ability in the Reading paper, while in the Speaking one this proportion was the lowest $-14 \%$.

Taking into consideration the above figures, we can make a conclusion that the Writing and Speaking papers are the least difficult due to the lowest percentage of weak ability and the highest percentage of borderline and good achievement demonstrated. At the same time the percentage of the exceptional ability in these papers is comparable to that in other exam papers.

Further analysis was carried out to identify the most difficult exam papers among the candidates obtaining the same grade $(A, B, C, B 1)$.

The following tables $4,5,6,7,8$ present the number of candidates with each grade and their proportion with respect to the total number of the examinees. Table 4 shows that all the candidates with Grade $A$ and more than half of the candidates with Grade B ( 6 out of 11 ) demonstrate an exceptional ability in the Reading paper.

The majority of the candidates with Grade $C$ (10 examinees out of 16$)$ achieved a good ability in this paper. The greatest difficulty in completing the Reading paper was experienced by the candidates whose performance is at B1 level 9 out of 12 demonstrated Borderline ability. Moreover, none of the candidates at this level showed an exceptional performance.

\section{Table 4}

\begin{tabular}{|c|c|c|c|c|}
\hline & \multicolumn{4}{|c|}{ Reading } \\
\hline Number of candidates / \% & Weak & Boderline & Good & Exceptional \\
\hline Total (44 candidates) & 10 & 14 & 8 & 12 \\
\hline Total (\%) & $23 \%$ & $32 \%$ & $18 \%$ & $27 \%$ \\
\hline A (5 candidates) & 0 & 0 & 0 & 5 \\
\hline A(\%) & $0 \%$ & $0 \%$ & $0 \%$ & $11 \%$ \\
\hline B (11 candidates) & 0 & 1 & 4 & 6 \\
\hline B(\%) & $0 \%$ & $2 \%$ & $9 \%$ & $14 \%$ \\
\hline C (16 candidates) & 1 & 10 & 4 & 1 \\
\hline C(\%) & $2 \%$ & $23 \%$ & $9 \%$ & $2 \%$ \\
\hline B1 (12 candidates) & 9 & 3 & 0 & 0 \\
\hline B1(\%) & $20 \%$ & $7 \%$ & $0 \%$ & $0 \%$ \\
\hline
\end{tabular}

Similarly, analyzing Paper 2 Writing, it was found out that that the overwhelming majority of the candidates succeeded in completing the tasks (Table 5). Interestingly, there isn't any significant difference in the exceptional writing ability among candidates with Grade A and those with Grade $\mathrm{C}$ - in both groups 2 candidates were identified. However, more than half of the candidates with Grade C (9 of 16) achieved only borderline. 
Table 5

\begin{tabular}{|c|c|c|c|c|}
\hline & \multicolumn{4}{|c|}{ Writing } \\
\hline Number of candidates / \% & Weak & Boderline & Good & Exceptional \\
\hline Total (44 candidates) & 3 & 20 & 11 & 9 \\
\hline Total (\%) & $7 \%$ & $45 \%$ & $25 \%$ & $20 \%$ \\
\hline A (5 candidates) & 0 & 2 & 1 & 2 \\
\hline A(\%) & $0 \%$ & $5 \%$ & $2 \%$ & $5 \%$ \\
\hline B (11 candidates) & 0 & 2 & 4 & 5 \\
\hline B(\%) & $0 \%$ & $5 \%$ & $9 \%$ & $11 \%$ \\
\hline C (16 candidates) & 1 & 9 & 4 & 2 \\
\hline C(\%) & $2 \%$ & $20 \%$ & $9 \%$ & $5 \%$ \\
\hline B1 (12 candidates) & 2 & 7 & 2 & 0 \\
\hline B1(\%) & $5 \%$ & $16 \%$ & $5 \%$ & $0 \%$ \\
\hline
\end{tabular}

Table 6 shows that only candidates whose performance is at B1 level had difficulties in completing the Use of English Paper - 9 out of 12 candidates failed to do the tasks, the other 3 candidates achieved only borderline . Most candidates with Grade A (4 of 5) and almost 50\% of the candidates with Grade B (5 out of 11) demonstrated an exceptional ability.

\section{Table 6}

\begin{tabular}{|c|c|c|c|c|}
\hline & \multicolumn{4}{|c|}{ Use of English } \\
\hline Number of candidates / \% & Weak & Boderline & Good & Exceptional \\
\hline Total (44 candidates) & 10 & 15 & 10 & 9 \\
\hline Total (\%) & $23 \%$ & $34 \%$ & $23 \%$ & $20 \%$ \\
\hline A (5 candidates) & 0 & 0 & 1 & 4 \\
\hline A(\%) & $0 \%$ & $0 \%$ & $2 \%$ & $9 \%$ \\
\hline B (11 candidates) & 0 & 1 & 5 & 5 \\
\hline B(\%) & $0 \%$ & $2 \%$ & $11 \%$ & $11 \%$ \\
\hline C (16 candidates) & 1 & 11 & 4 & 0 \\
\hline C(\%) & $2 \%$ & $25 \%$ & $9 \%$ & $0 \%$ \\
\hline B1 (12 candidates) & 9 & 3 & 0 & 0 \\
\hline B1(\%) & $20 \%$ & $7 \%$ & $0 \%$ & $0 \%$ \\
\hline
\end{tabular}

Listening Paper (Table 7) represents a significant challenge for most candidates with English proficiency B1 - 9 out of 12 examinees failed to complete this paper. The same is true for nearly every second candidate with grade $C$ (7 out of 16 ). The candidates with a higher level of proficiency (Grades A and B) didn't find considerable difficulties in performing the listening tasks.

\section{Table 7}

\begin{tabular}{|c|c|c|c|c|}
\hline & \multicolumn{4}{|c|}{ Listening } \\
\hline Number of candidates / \% & Weak & Boderline & Good & Exceptional \\
\hline Total (44 candidates) & 16 & 12 & 7 & 8 \\
\hline Total (\%) & $36 \%$ & $27 \%$ & $16 \%$ & $18 \%$ \\
\hline A (5 candidates) & 0 & 1 & 1 & 4 \\
\hline A( $\%)$ & $0 \%$ & $2 \%$ & $2 \%$ & $9 \%$ \\
\hline B (11 candidates) & 0 & 4 & 4 & 3 \\
\hline B(\%) & $0 \%$ & $9 \%$ & $9 \%$ & $7 \%$ \\
\hline C (16 candidates) & 7 & 6 & 2 & 1 \\
\hline C(\%) & $16 \%$ & $14 \%$ & $5 \%$ & $2 \%$ \\
\hline B1 (12 candidates) & 9 & 2 & 0 & 0 \\
\hline B1(\%) & $20 \%$ & $5 \%$ & $0 \%$ & $0 \%$ \\
\hline
\end{tabular}

Speaking paper was successfully performed by the great majority of the candidates -most candidates with grade B (9 out of 11 ) and $C$ (9 out of 16) showed a good speaking ability. A single examinee whose proficiency level is B1 demonstrated a weak ability, thus it can be considered as a failure in this paper. (Table 8) 


\section{Table 8}

\begin{tabular}{|c|c|c|c|c|}
\hline & \multicolumn{4}{|c|}{ Speaking } \\
\hline Number of candidates / \% & Weak & Boderline & Good & Exceptional \\
\hline Total (44 candidates) & 1 & 15 & 22 & 6 \\
\hline Total (\%) & $2 \%$ & $34 \%$ & $50 \%$ & $14 \%$ \\
\hline A (5 candidates) & 0 & 0 & 1 & 4 \\
\hline A(\%) & $0 \%$ & $0 \%$ & $2 \%$ & $9 \%$ \\
\hline B (11 candidates) & 0 & 1 & 9 & 1 \\
\hline B(\%) & $0 \%$ & $2 \%$ & $20 \%$ & $2 \%$ \\
\hline C (16 candidates) & 0 & 6 & 9 & 1 \\
\hline C(\%) & $0 \%$ & $14 \%$ & $20 \%$ & $2 \%$ \\
\hline B1 (12 candidates) & 1 & 8 & 4 & 0 \\
\hline B1(\%) & $2 \%$ & $18 \%$ & $9 \%$ & $0 \%$ \\
\hline
\end{tabular}

Traditionally, productive skills are considered to be more difficult to develop than receptive skills. However, present research refutes this assertion. In order to identify possible reasons for the relationship (or lack of relationship) between the proficiency level and performance in each exam paper, a further multiple factor analysis should be carried out. Candidates' age, preparation course attendance, overall study period and other factors have to be considered.

Nevertheless, our own experience in teaching and exam administering allows us to detect the sources of such imbalance, which might be the following.

Firstly, in the productive papers of the exam (Writing and Speaking) there is always an opportunity for a candidate to choose lexical and grammatical units which they have mastered and feel confident about. Obviously, this tends to yield maximum accuracy which greatly contributes to a final grade.

Secondly, in the receptive skills the lower English proficiency a candidate has, the more interference of the gaps in the student's knowledge is observed. For example, it's evident that weak reading ability may cause task misunderstanding which, in its turn, partially affects the performance in listening paper.

\section{Results}

The research leads to the following conclusion about the difficulty of the FCE papers depending on the level of candidates' language proficiency.

1. Regardless of the level of candidates' language proficiency, the least difficult papers are productive ones writing and speaking. The majority of candidates coped with these tasks; moreover, the performance of more than half of all candidates was rated as "good" and "exceptional".

2. Based on the number of "unsatisfactory" performance, listening paper is most difficult for $36 \%$ of the candidates. However, this difficulty was experienced only by candidates with a lower level of language proficiency (certificates with grade $\mathrm{C}$ and B1certificates).

3. Reading and Use of English papers are equally failed - $23 \%$ of the examinees didn't complete the tasks at the required level. However, in both papers only B1 level candidates contributed to this percentage.

4. To identify the sources of the difficulties in particular papers and relationship between the difficulty level of paper questions and language proficiency additional multiple factor analysis should be made.

\section{References}

Portuguese schools to use Cambridge English as part of national scheme. [Online] Available: http://www.cambridgeenglish.org/ news/view/portuguese-schools-to-use-cambridge-english-as-part-of-national-schemel. (February 28, 2014)

Cambridge English Language Assessment http://www.cambridgeenglish.org/http://www.cambridgeenglish.org/why-cambridge-english/ global-recognition/index.aspx?s=1

Cambridge English: First - First Certificate in English (FCE) CEFR Level B2. Handbook for Teachers. Cambridge: UCLES, 2012.

Cambridge English: First - First Certificate in English (FCE) CEFR Level B2. Specifications and Sample Papers for examinations from January 2015. Cambridge: UCLES, 2013.

Alderson J. (1999). Language Test Construction and Evaluation. New York: Cambridge University Press.

Bachman L. (1997). Language Testing in Practice: Designing and Developing Useful Language Tests. Oxford: Oxford University Press.

Common European Framework of Reference for Languages: Learning, teaching, assessment. - Cambridge: Cambridge University Press, 2001.

Hughes A. (2000). Testing for Language Teachers. Cambridge: Cambridge University Press.

Madsen H. (1983). Techniques in Testing. Oxford: Oxford University Press. 